\title{
THE SPEED OF DARK ENERGY
}

\author{
Faster than a speeding photon.
}

\section{BY JEFF HECHT}

$\mathrm{T}$ he university's Innovation Networking Conference was going poorly, like the rest of Boris's life. His postdoc was running out, and with no job in the offing, he faced a one-way flight back to Novosibirsk. His eight papers in theoretical astrophysics would earn him no more in Russia than in America, but at least he could sleep on his father's couch. Boris was brooding when he noticed a portly, well-dressed man reading his poster.

"May I help you?" Boris asked, as Professor Liu had told him to.

The man nodded. "This darkenergy stuff in your poster is what makes the Universe expand faster, right? How fast does it go?"

Professor Liu had said not to answer simple questions with abstruse mathematics. "Yes, it permeates space, but what velocity do you mean?"

"Can it move faster than light?"

That puzzled Boris. "Why do you want to know?"

The man looked into Boris's eyes, and his voice dropped to a whisper. "Because I need something faster than light for a consulting project."

"Well," said Boris, pausing to search for the right words in the hope of somehow landing a job, "I don't know why it couldn't move faster than light." His grandfather liked to tell of a colleague who told a Brezhnev-era general that he didn't know why he couldn't build a 10-megawatt laser weapon. That statement had earned the man a good job and a dacha, and because his statement was literally true and because Brezhnev wasn't Stalin, nobody had got shot when it didn't work after a dozen years.

"Stop by my office in the morning," the man said, handing Boris a card identifying him as Andrew Harrison Harding, professor of economics.

"Nanoseconds count," began Professor Harding. "What do you know about highfrequency automated trading?"

Boris shrugged.

"It's how the stock market works now. Computers buy and sell stock to each other, and we hope our computers outsmart theirs. The best way to outsmart them is to get information faster, so submarine fibreoptic cables run the shortest routes. One goes through the Arctic Ocean from Tokyo to London. Now our competitors are laying a hollow-core fibre along that route, and

interactions between dark energy and ordinary matter, then converted them into code for models to run on the quantum computer and his desktop supercomputer.

He tested the models for weeks, pored over the results, rewrote the code, and ran the models again. The results mapped the distribution of dark energy relative to matter, so he calculated the rate of change and converted that into velocity. His first velocity results were close to zero, so he changed his reference frame, and found that the velocities were a little higher when he computed over more space. Impatient, he increased the scale by ten orders of magnitude and left the model running over the weekend, hoping that the computing strain wouldn't melt anything.

His desktop's fans howled like a wind tunnel on Monday morning when he asked it to display the results on a wall screen. The pattern looked familiar, but when he checked the colour scale, he was amazed to find that the yellow midpoint was the speed of light, and vast areas of green and blue showed superluminal velocities.

Professor Harding arrived minutes after Boris called him, and

because light goes faster through the empty core than through a solid glass fibre, it will be faster than our cable. So we need to send data faster than light. Can dark energy do it?"

"It may in some places," Boris answered, not mentioning that those places were beyond the observable Universe. "It would take time to work out the details."

"I can pay you good money to do that."

Boris could invent equations, not cable systems, but this was no time to mention that. "I will need resources," he said.

"I have office space and access to the university's quantum computer." The professor paused. "You can start at $\$ 2,000$ a week on Monday."

Boris smiled. Professor Liu would be amazed.

Boris enjoyed theory. He filled bound $\rightarrow$ NATURE.COM

Follow Futures: @NatureFutures

f go.nature.com/mtoodm quadrille-ruled notebooks with symbols and equations. He wrote mathematical descriptions of the stared at the wall screen. "We're going to be rich!" he said. "Route the cable like this," he said, sweeping his arm on an arc.

"No cable," Boris said. "Dark energy permeates everything, so it goes through Earth."

"Better yet," said the professor. "Write this up and we'll patent it. Investors will be pounding on the door. I'll double your salary."

After Professor Harding left, Boris fiddled with the display. Curious how much space the model covered, he asked the supercomputer to show the linear scale. Small words appeared near the bottom: "Width of region shown, $10^{12}$ light years." For a few minutes, he felt very proud of himself for modelling beyond the edge of the observable Universe. Then he realized that the only superluminal velocities were beyond the edge. He was only a few orders of magnitude off. Maybe he could forestall the bad news as long as his grandfather's friend had.

Jeff Hecht is Boston correspondent for New Scientist and contributing editor to Laser Focus World. 